4-16-2014

\title{
Thoracic and lumbar spinal surgery under local anesthesia for patients with multiple comorbidities: A consecutive case series
}

Muhammad Babar Khan

Rajesh Kumar

Ather Enam

Follow this and additional works at: https://ecommons.aku.edu/pakistan_fhs_mc_surg_neurosurg

Part of the Neurology Commons, Neurosurgery Commons, and the Surgery Commons 


\title{
Thoracic and lumbar spinal surgery under local anesthesia for patients with multiple comorbidities: A consecutive case series
}

\author{
Muhammad Babar Khan, Rajesh Kumar, Syed Ather Enam \\ Section of Neurosurgery, Department of Surgery, Aga Khan University Hospital, Karachi, Pakistan \\ E-mail: Muhammad Babar Khan - babarkhan08@gmail.com; Rajesh Kumar - rajesh.kumar@aku.edu; *Syed Ather Enam - ather.enam@aku.edu \\ *Corresponding author
}

Received: 22 August $13 \quad$ Accepted: 03 January $14 \quad$ Published: I6 April I4

This article may be cited as:

Khan MB, Kumar R, Enam SA. Thoracic and lumbar spinal surgery under local anesthesia for patients with multiple comorbidities:A consecutive case series. Surg Neurol Int 2014;5:S62-5.

Available FREE in open access from: http://www.surgicalneurologyint.com/text.asp?2014/5/4/62/130669

Copyright: @ 2014 Khan MB.This is an open-access article distributed under the terms of the Creative Commons Attribution License, which permits unrestricted use, distribution, and reproduction in any medium, provided the original author and source are credited.

\begin{abstract}
Background: Although some patients with symptomatic spinal disease may benefit greatly from surgery, their multiple attendant comorbidities may make general anesthesia risky or contraindicated. However, there is scarce literature describing the efficacy and safety of local anesthesia to perform these operations. Here we report seven patients who successfully underwent spinal surgery utilizing local anesthesia to limit the risks and complications of general anesthesia.

Methods: Seven patients for whom general anesthesia was contraindicated were prospectively followed for a minimum of 3 months following spinal surgery performed under local anesthesia. Pain and functional improvement were assessed utilizing the Visual Analog Scores (VAS) and Oswestry Disability Index (ODI) scores.

Results: Five patients had interlaminar decompressions for stenosis alone, while two patients had laminectomies for debulking of tumors. The mean duration of surgery was $79.8 \pm 16.6 \mathrm{~min}$, the mean estimated blood loss was $157.1 \pm 53.4 \mathrm{ml}$, the mean dose of local anesthetic was $1.9 \pm 0.7 \mathrm{mg} / \mathrm{kg}$, and the mean length of hospital stay after surgery was $3.2 \pm 1.2$ days. There were no intraoperative complications. The surgery resulted in improved VAS and ODI scores consistent with significant improvement in pain $(P=0.017)$ and functionality $(P=0.011)$.

Conclusions: Performing spinal surgery under local anesthesia is a safe and effective alternative when patient's major comorbidities preclude a general anesthetic. For all the seven patients studied, spinal surgery, performed under a local anesthetic, resulted in a statistically significant reduction in pain and improvement in function.
\end{abstract}

Key Words: Debulking, interlaminar decompression, local anesthesia, lumbar, multiple comorbidities, spinal surgery, thoracic

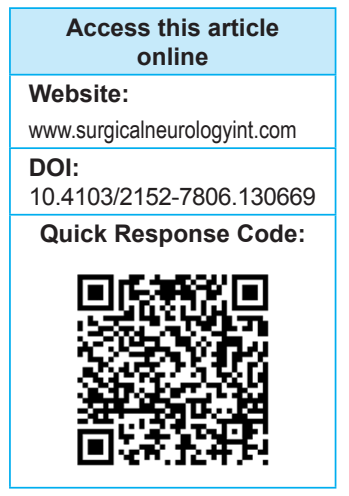

\section{INTRODUCTION}

Patients with symptomatic degenerative spinal disorders (e.g. disc herniation/stenosis) or metastatic cancers may require spinal surgery consisting of decompressive laminectomies, but cannot tolerate a general anesthetic due to multiple attendant morbidities. $^{[1]}$ Here we ask whether some of these patients would benefit from spinal surgery performed under local anesthesia. 
Performing spinal surgery utilizing a local anesthetic is not a new concept, particularly when performed in healthy patients. ${ }^{[3,6,7]}$ Indeed, in 1926, Towne reported that four patients had laminectomies to remove tumors under local anesthesia. ${ }^{[7]}$ Other similar series have been reported since then. ${ }^{[3,6]}$

Our literature search yielded only one study involving 10 patients with American Society of Anesthesiologists (ASA) physical status score of III or higher managed with local anesthesia. ${ }^{[1]}$ Other more recent studies have favorably compared the use of local anesthesia to general anesthesia for lumbar spinal decompressions in medically fit individuals. ${ }^{[2]}$ Here, we report a series of seven consecutive patients who required spinal surgery that were successfully performed under local anesthesia, as their ASA scores of III or IV precluded the use of a general anesthetic.

\section{MATERIALS AND METHODS}

\section{Patient population}

This study included seven consecutive patients in whom general anesthesia was contraindicated due to multiple comorbidities (e.g. ASA scores of III or IV) [Table 1]. Surgical indications included severe debilitating pain refractory to nonsurgical management in three patients or progressive neurological deficits and debilitating pain refractory to nonsurgical management in four patients.

Surgical procedures local anesthetic technique In five patients, bilateral laminotomies with medial facetectomies were performed to decompress central/lateral stenosis and ossified yellow ligament (OYL) under the operating microscope [Figure 1]. For two patients, a midline, bilateral laminectomy was performed for epidural tumor debulking [Figure 2].

Patients were premedicated with meperidine $(50 \mathrm{mg})$, promethazine $(25 \mathrm{mg})$ and cefuroxime $(1.5 \mathrm{~g})$. They were mildly sedated with meperidine $(15-35 \mathrm{mg} / \mathrm{h}$ continuous infusion) and fentanyl ( $1-2 \mathrm{mcg} / \mathrm{kg} / \mathrm{h}$ continuous infusion) allowing for continuous verbal contact throughout the

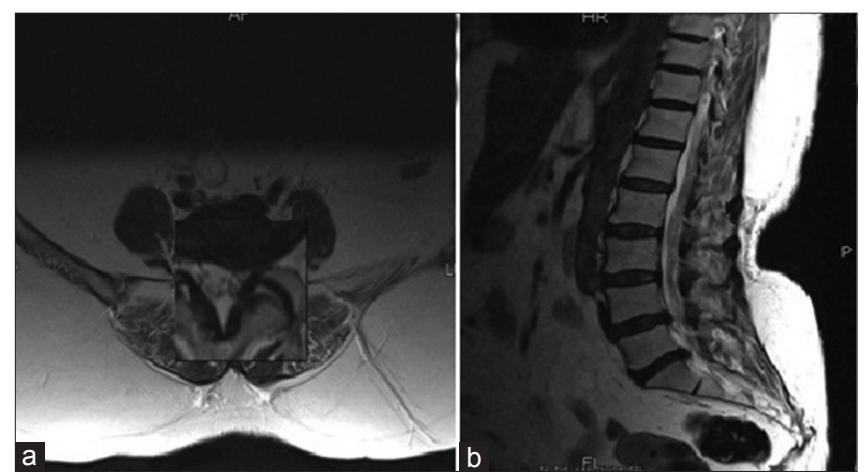

Figure I: Preoperative scans from a patient who underwent interlaminar decompression. (a) Axial section of L4-L5 vertebral level showing marked foraminal stenosis on the left side.(b) Sagittal sections showing disc herniation at L4-L5 and L5-SI levels procedure. Ten milliliters of $2 \%$ lidocaine with 1:200,000 adrenaline was infiltrated into the skin overlying the incision site and into the deep tissues. During surgery, the patients received additional injections of a local anesthetic if they complained of pain. This was administered only after consultation with the anesthesiologists, making sure that the patients vital signs were stable, and that the total dose did not exceed $7 \mathrm{mg} / \mathrm{kg}$ [Table 2].

Intraoperative monitoring routinely included blood pressures, pulse oximetry, electrocardiogram, and cutaneous temperature probes. Postoperatively, patients had access to patient controlled intravenous analgesia (PCIA) for the duration of their hospital

Table 1: Preoperative patient characteristics

\begin{tabular}{lccc}
\hline $\begin{array}{l}\text { Presenting patient } \\
\text { characteristics }\end{array}$ & Number & Range & Mean \pm (SD) \\
\hline $\begin{array}{l}\text { Age (years) } \\
\text { Sex }\end{array}$ & 7 & $53-79$ & $65.3 \pm 10.6$ \\
$\quad$ Male & 4 & & \\
Female & 3 & & \\
ASA & & & \\
III & 4 & \\
IV & 3 &
\end{tabular}

Comorbidities

Hypertension 6

Asthma 4

Diabetes 3

Colon cancer 2

Mitral regurgitation 2

Hepatitis C 2

Stroke 1

Ischemic heart disease 1

Hypothyroidism 1

Depression 1

$\begin{array}{llll}\text { VAS score } & 7 & 5-7 & 6.14 \pm 0.69\end{array}$

ODI score (\%) $\quad 7 \quad 68-83 \quad 77.2 \pm 8.3$

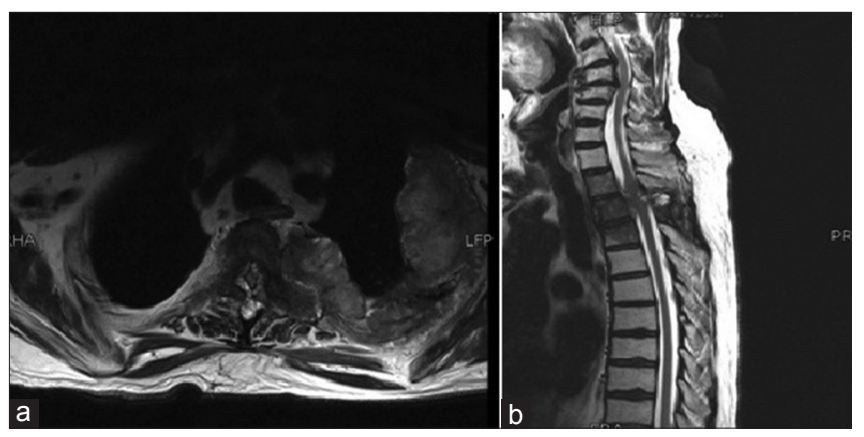

Figure 2: Preoperative scans from a patient who underwent laminectomy and tumor excision. (a) axial section and (b) sagittal section showing metastatic involvement of posterior elements of T3 with significant epidural component resulting in marked compression of the cord with contour deformity. Left paravertebral body can also be appreciated with involvement of the transverse process. Involvement of vertebral bodies of TI,T2 and T3 can also be seen 
Table 2: Summary of patient management and outcomes

\begin{tabular}{|c|c|c|c|c|}
\hline & Number & Range & Mean \pm SD & $P$ value \\
\hline \multicolumn{5}{|l|}{ Spine levels operated } \\
\hline L4-L5 & 2 & & & \\
\hline L3-L5 & 2 & & & \\
\hline L3-L4 & 1 & & & \\
\hline T2-T3 & 1 & & & \\
\hline T5-T6 & 1 & & & \\
\hline Blood loss (ml) & 7 & $100-200$ & $157.1 \pm 53.4$ & \\
\hline Duration (min) & 7 & $63-95$ & $79.8 \pm 16.6$ & \\
\hline Local anesthetic used $(\mathrm{mg} / \mathrm{kg})$ & 7 & $3.2-5.9$ & $4.5 \pm 1.3$ & \\
\hline Postoperative hospital stay (days) & 7 & $2-5$ & $3.2 \pm 1.2$ & \\
\hline Postoperative follow up (months) & 7 & $7-18$ & $11.4 \pm 3.8$ & \\
\hline \multicolumn{5}{|l|}{ VAS } \\
\hline Preoperative & 7 & $5-7$ & $6.14 \pm 0.69$ & 0.017 \\
\hline Postoperative & 7 & $0-2$ & $0.71 \pm 0.76$ & \\
\hline \multicolumn{5}{|l|}{ ODI } \\
\hline Preoperative & 7 & $69-85$ & $77.2 \pm 8.3$ & 0.011 \\
\hline Postoperative & 7 & $18-30$ & $24.3 \pm 5.8$ & \\
\hline
\end{tabular}

admission (range 2-5 days). They were typically discharged on pregabalin, muscle relaxants, and tramadol hydrochloride for two postoperative weeks.

Outcome assessment and statistical analysis Outcomes assessment was done 3 months postoperatively. Pain improvement was assessed utilizing Visual Analog Scale (VAS) scores, while functional improvement was gauged with the Oswestry Disability Index (ODI). Data were analyzed using IBM SPSS statistics for Windows version 20 (IBM, Armonk, NY). A Wilcoxon matched pairs test was used to check the statistical significance of change in preoperative and postoperative VAS and ODI scores. A $P$ value of less than 0.05 was considered statistically significant.

\section{RESULTS}

All patients showed a statistically significant improvement in VAS scores (decreased from a mean of 6.14-0.71 $[P=0.017]$ ) and ODI scores (decreased from a mean of $77.2-24.3 \%[P=0.011])$ [Table 2]. There were no intraoperative complications. Postoperatively, one patient developed a surgical site infection, and one patient had a urinary tract infection. There was no statistically significant correlation between ASA scores and the development of these complications. All the procedures were carried out under local anesthesia; none had to be converted to a general anesthetic.

\section{DISCUSSION}

ASA physical status has been shown to correlate with perioperative variables, postoperative complications, and mortality rates with the risks mainly being influenced by
ASA class IV (odds ratio $=4.2$ ) and ASA class III (odds ratio $=2.2){ }^{[8]}$ The increased risk of complications associated with these high ASA scores often preclude neurosurgical spinal intervention. ${ }^{[1]}$ Four of our patients were ASA class III, while three patients were ASA class IV; each patient had an average of three major comorbidities. The number of complications, rate of improvement (VAS, ODI), and overall outcomes were comparable for patients in either class III or IV. Therefore, spinal surgery performed under local anesthesia for these patients with major comorbidities precluding a general anesthetic, appeared to both safe and effective.

The operation was generally well tolerated with exception of the discomfort felt during the retraction of paraspinal muscles and manipulation of the dural sac or nerve roots reported to varying extents by almost all patients; this finding has also been previously reported. ${ }^{[1,2]}$ We believe that delicate handling of tissue and well targeted infiltration of a local anesthetic can decrease patients' discomfort during retraction of the paraspinal muscles. Furthermore, we placed a pack soaked in local anesthetic over the thecal sac for a few minutes before manipulating the dural sac or nerve roots, and found that this substantially minimized patient discomfort.

We as well as other authors have observed that most patients found laying still for the duration of surgery (especially after $90 \mathrm{~min}$ ) difficult. ${ }^{[1]}$ Therefore, reducing the time of surgery to maximize patient comfort is critical. Spontaneous breathing under local anesthesia reduces intrathoracic pressures and hence bleeding. ${ }^{[4]}$ Moreover, adrenaline added to the local anesthesia also decreases blood loss. Meticulous planning of abridged procedures should additionally reduce operative time 
and its attendant risks. Another advantage of utilizing a local anesthetic on patients undergoing spinal procedures is that one can utilize awake monitoring. ${ }^{[1,2,5,6]}$ This can guide the surgeon to avoid excessive neural manipulation/ damage, and facilitate monitoring in real- time.

\section{Risks of local anesthesia for spinal surgery}

Previously, focus was placed on the risks of utilizing local anesthesia for spinal surgery, including toxicity associated with high local anesthetic doses, and venous air embolism. None of our patients suffered from any local anesthesia-related toxicity; this is consistent with other reports in the literature. ${ }^{[1,2,6]}$ Furthermore, the risk of air embolism is virtually nonexistent unless the patient is in a unique head up position. ${ }^{[1,6]}$

\section{CONCLUSION}

Spinal surgery may be safely performed utilizing a local anesthetic in patients who are not candidates for a general anesthetic due to attendant major comorbidities (e.g. ASA scores of III or IV). In the seven patients presented in this series, spinal surgery performed under local anesthesia resulted in significant improvement in pain and functionality.

\section{REFERENCES}

I. AmesWA, Songhurst L, Gullan RW. Local anaesthesia for laminectomy surgery. $\mathrm{Br}$ J Neurosurg 1999;13:598-600.

2. Chen HT, Tsai CH, Chao SC, Kao TH, Chen YJ, Hsu HC, et al. Endoscopic discectomy of L5-SI disc herniation via an interlaminar approach:Prospective controlled study under local and general anesthesia. Surg Neurol Int 20II;2:93.

3. Greenbarg PE, Brown MD, Pallares VS, Tompkins JS, Mann NH. Epidural anesthesia for lumbar spine surgery. J Spinal Disord 1988; I:139-43.

4. Jellish WS, Thalji Z, Stevenson K, Shea J. A prospective randomized study comparing short-and intermediate-term perioperative outcome variables after spinal or general anesthesia for lumbar disk and laminectomy surgery. Anesth Analg 1996;83:559-64.

5. McLain RF, Kalfas I, Bell GR, Tetzlaff JE, Yoon HJ, Rana M. Comparison of spinal and general anesthesia in lumbar laminectomy surgery: $A$ case-controlled analysis of 400 patients. J Neurosurg Spine 2005;2: 17-22.

6. Nygaard OP, Romner B, Thoner J, Due-Tonnessen B. Local anesthesia in posterior cervical surgery. Anesthesiology 1997;86:242-3.

7. Towne EB. Laminectomy and removal of spinal cord tumors under local anesthesia. Cal West Med 1926;24:194.

8. Wolters U, Wolf T, Stützer H, Schröder T. ASA classification and perioperative variables as predictors of postoperative outcome. $\mathrm{Br}$ JAnaesth 1996;77:217-22. 